\title{
Reliability of maximum isometric arm, grip and pinch strength measurements in children (7-12 years) with unilateral spastic cerebral palsy
}

Citation for published version (APA):

Dekkers, K., Janssen-Potten, Y., Gordon, A. M., Speth, L., Smeets, R., \& Rameckers, E. (2020).

Reliability of maximum isometric arm, grip and pinch strength measurements in children (7-12 years) with unilateral spastic cerebral palsy. Disability and Rehabilitation, 42(10), 1448-1453.

https://doi.org/10.1080/09638288.2018.1524522

Document status and date:

Published: 07/05/2020

DOI:

10.1080/09638288.2018.1524522

Document Version:

Publisher's PDF, also known as Version of record

\section{Document license:}

Taverne

Please check the document version of this publication:

- A submitted manuscript is the version of the article upon submission and before peer-review. There can be important differences between the submitted version and the official published version of record.

People interested in the research are advised to contact the author for the final version of the publication, or visit the DOI to the publisher's website.

- The final author version and the galley proof are versions of the publication after peer review.

- The final published version features the final layout of the paper including the volume, issue and page numbers.

Link to publication

\footnotetext{
General rights rights.

- You may freely distribute the URL identifying the publication in the public portal. please follow below link for the End User Agreement:

www.umlib.nl/taverne-license

Take down policy

If you believe that this document breaches copyright please contact us at:

repository@maastrichtuniversity.nl

providing details and we will investigate your claim.
}

Copyright and moral rights for the publications made accessible in the public portal are retained by the authors and/or other copyright owners and it is a condition of accessing publications that users recognise and abide by the legal requirements associated with these

- Users may download and print one copy of any publication from the public portal for the purpose of private study or research.

- You may not further distribute the material or use it for any profit-making activity or commercial gain

If the publication is distributed under the terms of Article 25fa of the Dutch Copyright Act, indicated by the "Taverne" license above, 


\title{
Reliability of maximum isometric arm, grip and pinch strength measurements in children (7-12 years) with unilateral spastic cerebral palsy
}

\author{
Koen Dekkers ${ }^{\mathrm{a}, \mathrm{b}, \mathrm{c}}$ (D), Yvonne Janssen-Potten ${ }^{\mathrm{b}, \mathrm{d}}$, Andrew M. Gordon ${ }^{\mathrm{e}}$, Lucianne Speth ${ }^{\mathrm{b}, \mathrm{d}}$, Rob Smeets ${ }^{\mathrm{b}, \mathrm{f}}$ and \\ Eugene Rameckers ${ }^{b, c, d, g}$

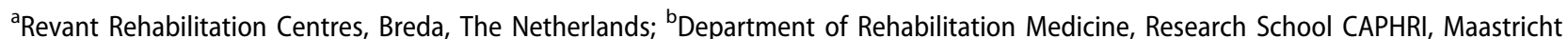 \\ University, Maastricht, The Netherlands; ' University for Professionals for Pediatric Physical Therapy, AVANSplus, Breda, The Netherlands;

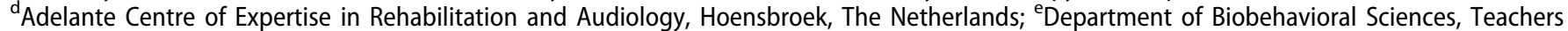 \\ College, Columbia University, New York, NY, USA; ${ }^{f}$ Libra Rehabilitation and Audiology, Eindhoven/Weert, The Netherlands; ${ }^{9}$ Faculty of Medicine \\ \& Health Science, Pediatric Rehabilitation, Biomed, Hasselt University, Hasselt, Belgium
}

\begin{abstract}
Purpose: To investigate test-retest and inter-rater reliability of maximum isometric arm muscle strength measurements using the hand-held dynamometer (HDD) and maximum isometric grip and pinch strength measurements using the Biometrics E-Link Evaluation System in children aged 7-12 years with unilateral spastic cerebral palsy.

Materials and methods: All data were obtained using a test-retest study design. The study met the conditions of the COSMIN criteria to achieve good methodological quality.

Results: For arm strength measurements, all test-retest reliability intraclass correlation coefficient (ICC) values and all but one inter-rater reliability ICC value indicated excellent reliability. For grip- and pinch strength measurements, all test-retest reliability and inter-rater reliability ICC values showed excellent reliability. The standard error of measurement values ranged from 4.97 to $11.36 \mathrm{~N}$ (HDD) and 0.37 to $1.81 \mathrm{~kg}$ (E-link). Smallest detectable change values ranged from 13.79 to $31.49 \mathrm{~N}$ (HDD) and 1.03 to $5.02 \mathrm{~kg}$ (E-link).

Conclusions: The HDD and E-link system are usable measurement instruments for cross-sectional muscle strength measurements in children with unilateral spastic cerebral palsy. It is not clear if both instruments are usable to measure changes in muscle strength within an individual, especially if a child with unilateral spastic cerebral palsy has low muscle strength. Caution in the interpretation of changes in muscle strength is therefore necessary.
\end{abstract}

\section{ARTICLE HISTORY}

Received 9 November 2017

Revised 11 September 2018

Accepted 12 September 2018

\section{KEYWORDS}

Unilateral cerebral palsy; muscle strength; arm strength; grip strength; reliability; clinimetric properties; hemiplegia; children

\section{- IMPLICATIONS FOR REHABILITATION}

- The hand-held dynamometer and E-Link Evaluation System are reliable measurement instruments to measure muscle strength of the arm and hand in children with unilateral spastic cerebral palsy, aged 7-12 years.

- Cross-sectional measurements; it is possible to measure upper extremity muscle strength in children with unilateral spastic cerebral palsy with the hand-held dynamometer and E-link system.

- Longitudinal measurements; changes in upper extremity muscle strength within one person should be interpreted with care, especially if a child with unilateral spastic cerebral palsy has low muscle strength.

\section{Introduction}

Abnormal gross and fine motor functioning and organization (reflecting abnormal motor control) are the core features of unilateral spastic cerebral palsy (USCP) [1]. In children with USCP, the muscles of the affected upper extremity (UE) are typically weaker than those of the contralateral UE and the strength of the UE of typically developing peers [2-4]. Muscle weakness of the UE may lead to limitations in daily activities, as grip strength has shown to be an important predictor of use of the affected arm in bimanual performance in children with USCP $[5,6]$.

Muscle strength in children with USCP could be measured for different reasons. Sometimes one needs to know if muscle strength could contribute to problems carrying out activities of daily living. Another reason could be if a therapist wants to know if muscle strength is gained after a strength training program. Strength training programs are recommended starting at 7 years of age [7]. Intensive strength training programs are often delivered to children in elementary school.

Several methods are available to measure muscle strength: dynamic (concentric, eccentric, isotonic, and isokinetic) and static (isometric). Dynamic muscle strength measurements may be influenced by spasticity as well as by limitations in the range of motion of the UE. In static/isometric muscle strength measurements, the ability of a muscle group to produce force without a change in overall muscle-tendon length is measured; therefore, limitations by spasticity and range of motion will not interfere 
with task performance during this measurement. Furthermore, in most daily activities the affected UE is used as an assisting hand (e.g., holding, stabilizing, carrying), and in these tasks a high percentage of maximum isometric muscle strength is needed.

(Isometric) muscle strength must be measured accurately; therefore, the instrument should have sound clinometric properties. A recent systematic review on the clinometric properties of measurement instruments for measuring UE strength in children with USCP concluded that research on clinometric properties is rarely conducted, and caution is needed regarding interpretation of the test results. Only reliability has been studied, and most of the available studies were of poor methodological quality [8]. Future studies should be designed according to the Consensusbased Standards for the selection of health Measurement INstruments (COSMIN) criteria and should use a well-described protocol. The hand dynamometer is recommended for measurement of grip strength. For measuring other UE muscle groups, it was recommended that the hand-held dynamometer (HDD) be used [8].

Reliability is an important clinometric property. One needs to know the degree to which variations in measurement appear when no changes in the disease or disorder have occurred. This so-called measurement error can arise from several sources: the measurement instrument itself, the person(s) assessing the measurement, the patient undergoing the measurement and the circumstances under which the measurement is performed [9]. Two important components of reliability are the standard error of the measurement (SEM) and smallest detectable change (SDC) [9]. The SEM is a measure of how far apart the outcomes of repeated measurements are; it is the standard deviation (SD) around a single measurement [9]. The SDC is the smallest change in score that you can detect with the instrument, above measurement error in individual patients [9]. To date, no data on SEM and SDC of the hand dynamometer and HHD in children with USCP are available in literature.

The purpose of this paper is to investigate the test-retest and inter-rater reliability (including SEM and SDC) of maximum isometric arm strength (IAS) measurements using the HHD and maximum isometric grip and pinch strength (IGPS) measurements using the Biometrics E-Link Evaluation System (digitalized handdynamometer), in children with USCP in a study of good methodological quality according to the COSMIN criteria [10] (see Supplementary Table S1 for the COSMIN criteria).

\section{Materials and methods}

\section{Study design}

All data were obtained using a test-retest study design. Data were collected in the Netherlands and USA, from 2009 to 2016.

\section{Participants}

Permission was granted by the Medical Ethical Board of the Maastricht University Medical Center and Maastricht University (METC azM/UM) in the Netherlands and at Teachers College, Columbia University in New York City, USA. In the Netherlands, the children were recruited from four different rehabilitation centres and related schools for special education, i.e., Adelante Rehabilitation Centre, Valkenburg, Libra Rehabilitation and Audiology, Tilburg, Revant Rehabilitation Centers, Breda and Goes, and Tolbrug Rehabilitation Centre, Den Bosch. In the USA, participants were a convenience sample of children participating in ongoing intensive UE studies at Teachers College, Columbia University.

This study focused on children with predominantly USCP between 7 and 12 years of age. The diagnosis USCP was based on the classification used by the child's neurologist or paediatrician. They were classified as Gross Motor Function Classification System (GMFCS) [11] I-II and Manual Ability Classification System (MACS) [12] levels I, II, or III. All participants were capable of following simple instructions. A child was excluded when he/she had undergone surgery or Botulinum Toxin-A treatment in the UE in the past 6 months. A child was excluded from the test-retest reliability measurements if he/she was participating in an intensive UE training program between the two measurements. There was no minimum muscle strength required to participate.

\section{Procedure}

Children were tested at the location from where they were recruited. A standardized protocol, with detailed descriptions of all procedures and measurements, was used (see Supplementary material). Prior to testing, body weight, MACS [12] and GMFCS [11] level were determined.

In USCP it is stated that increased muscle tone and weakness are most pronounced in distal muscle groups [6]. Accordingly, we decided to only test elbow, wrist and hand (grip/pinch) strength. In each child, a pre-randomized mix of measurements, using the random.org app (mobile application software) [13] was used. Each measurement was performed three consecutive times. Between each measurement, the child had at least 30 seconds of rest to allow for muscle recovery. In each test, both the affected hand $(\mathrm{AH})$ and the non-affected hand $(\mathrm{NAH})$ were measured. The $\mathrm{NAH}$ was tested before the $\mathrm{AH}$.

For each measurement, the child was seated in an upright position in a chair with back support and armrests. For all measurements, the armrests of the chair were used to support the arms during testing. The initial posture was neutral position $\left(0^{\circ}\right)$ of the wrist joint and $90^{\circ}$ flexion of the elbow joint.

With the HHD, isometric wrist extension with stretched fingers, wrist extension with flexed fingers, wrist flexion with stretched fingers and elbow flexion/extension were measured. With the E-Link Evaluation System, IGPS were measured. The handle position of the E-link handgrip was adapted to the child's hand size, according to the E-link guideline for positioning. The child was also asked whether the position of the handle felt the best. When there was doubt, other handle positions were tried.

Test scores were read by the therapist and registered by the same therapist on a test form. For the E-Link Evaluation System, test scores were also stored on the E-Link Evaluation System computer. Children were verbally encouraged by the therapist to produce maximum force, by saying "hard, harder, hardest" in a time span of $4-5$ seconds.

To evaluate test-retest reliability, the standardized protocol was conducted two times by the same therapist within 2-4 weeks. This time interval was chosen because during normal development (without intensive UE training) no muscle strength loss or gain was expected, and the possible motivation/influence of the therapist/child to score the same result as during the first measurement (because the first result could be remembered by the child/therapist) was minimal. For the second time, test conditions were kept identical.

To evaluate inter-rater reliability, the standardized protocol was conducted two times on the same day, by two different therapists. There was approximately 30 minutes of rest between 
each assessment. This rest period was judged sufficient for the child to recover and limited the possibility for personal and environmental factors to change.

All measurements were performed by eight (paediatric) physical therapists, who had no direct professional connection with the participants. All the therapists performed the measurements in the Netherlands. Two of them also performed the measurements in the USA. They had four hours of training by an experienced paediatric physical therapist on how to use the standardized protocol in children with USCP.

\section{Measures}

\section{Isometric arm strength}

Maximum IAS was measured with the Microfet 2 HHD (Hoggan Scientific, LLC, Salt Lake City, UT). An HHD is an electronic device that fits in the palm of a hand. A load cell (strain gauge technology) measures the isometric muscle strength applied to a transducer. The "make method", in which the child applies force against a fixed HHD, was used [14]. The applied force was measured in Newtons.

\section{Isometric grip and pinch strength}

Maximum IGPS of both $\mathrm{AH}$ and $\mathrm{NAH}$ were measured with the Biometric E-Link Evaluation System (Biometrics Ltd, Gwent, UK). As lateral pinch/key pinch is the easiest in children with USCP, this pinch position was chosen. The E-Link Evaluation System is a calibrated, computerized system incorporating a modified (digitalized) grip dynamometer and a pinch meter. The applied force was measured in $0.1 \mathrm{~kg}$.

\section{Statistical analysis}

For each test, the mean of three measurements was calculated. In this way, variability in muscle strength due to variations in placing the measurement instrument on a prescribed measurement spot (and therefore a smaller or larger torque arm) was minimized. Intraclass correlation coefficients (ICC), model two way random, type absolute agreement, with a 95\% confidence interval (Cl) were used to assess test-retest reliability and inter-rater reliability. An ICC $>0.80$ reflects excellent reliability, while ICCs from 0.70 to 0.79 reflect good reliability [15].

The SEM agreement was calculated as the square root of the error variance (including the systematic error) [9]. The SDC was computed as 1.96 multiplied by the square of 2, multiplied by the SEM $(S D C=1.96 \times \sqrt{ } 2 \times$ SEM) [9].

\section{Results}

A total of 86 children (53 boys, 33 girls; mean age 9 years, 3 months, SD 1 year 8 months) with USCP participated in this study. Their parents (and children aged 12 years) provided informed consent for participation. Due to the availability of the child and/ or measurement instrument or because the child met the exclusion criterion for the test-retest reliability study, some children only performed the measurements of the test-retest reliability and some only the measurements of the inter-rater reliability. Therefore, the sample sizes vary across the measurements. Participant characteristics per measurement are provided in Table 1.

\section{Test-retest reliability}

For the IAS, 52 children performed all measurements. For the IGPS, the total number of participants was 65 . There were no missing items. The test-retest reliability statistics of the IAS and IGPS are presented in Table 2.

Table 1. Participants characteristics.

\begin{tabular}{|c|c|c|}
\hline \multirow{2}{*}{$\begin{array}{l}\text { Measurement } \\
\text { Total group }\end{array}$} & \multicolumn{2}{|c|}{ Characteristics } \\
\hline & Age group & Gender mix \\
\hline $\begin{array}{l}\text { Test-retest reliability study } \\
\text { Isometric Arm Strength measurements (HHD) } \\
n=52.33 \hat{0}, 19 \text {. } \\
\text { Mean age } 9.3 \text { years, SD } 1.9 \text { years. } \\
35 \text { right side affected, } 17 \text { left side affected. } \\
\text { MACS level; I: } n=16, \text { II: } n=28 \text {, III: } n=4 \text {, missing } n=4\end{array}$ & $\begin{array}{l}\text { Age } 7, n=13 \\
\text { Age } 8, n=10 \\
\text { Age } 9, n=7 \\
\text { Age } 10, n=5 \\
\text { Age } 11, n=6 \\
\text { Age } 12, n=11\end{array}$ & $\begin{array}{l}6 \hat{\jmath}, 79 \\
4 \hat{\jmath}, 6 q \\
5 \hat{\jmath}, 2 q \\
4 \hat{\jmath}, 19 \\
5 \hat{\jmath}, 19 \\
9 \hat{\jmath}, 2+\end{array}$ \\
\hline $\begin{array}{l}\text { Isometric grip and pinch strength measurements (E-link system) } \\
n=65,41,24+\text {. } \\
\text { Mean age } 9.2 \text { years, SD } 1.8 \text { years. } \\
40 \text { right side affected, } 25 \text { left side affected. } \\
\text { MACS level; I: } n=21, \text { II: } n=33, \text { III: } n=7 \text {, missing } n=4\end{array}$ & $\begin{array}{l}\text { Age } 7, n=15 \\
\text { Age } 8, n=12 \\
\text { Age } 9, n=12 \\
\text { Age } 10, n=5 \\
\text { Age } 11, n=10 \\
\text { Age } 12, n=11\end{array}$ & $\begin{array}{l}7 \hat{\sigma}, 8+ \\
5 \hat{\jmath}, 7+ \\
7 \hat{\delta}, 5+ \\
4 \hat{\jmath}, 19 \\
9 \hat{\alpha}, 19 \\
9 \hat{\jmath}, 29\end{array}$ \\
\hline $\begin{array}{l}\text { Inter-rater reliability study } \\
\text { Isometric arm strength measurements (HHD) } \\
n=53,31 \hat{\jmath}, 22 \text {. } \\
\text { Mean age } 9.0 \text { years, SD } 1.7 \text { years. } \\
31 \text { right side affected, } 22 \text { left side affected. } \\
\text { MACS level; I: } n=15, \text { II: } n=29, \text { III: } n=4 \text {, missing } n=5\end{array}$ & $\begin{array}{l}\text { Age } 7, n=14 \\
\text { Age } 8, n=11 \\
\text { Age } 9, n=9 \\
\text { Age } 10, n=8 \\
\text { Age } 11, n=3 \\
\text { Age } 12, n=8\end{array}$ & 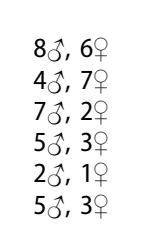 \\
\hline $\begin{array}{l}\text { Isometric grip and pinch strength measurements (E-link system) } \\
n=54,31 \hat{\delta}, 23 \text { +. } \\
\text { Mean age } 9.0 \text { years, SD } 1.7 \text { years. } \\
31 \text { right side affected, } 22 \text { left side affected. } \\
\text { MACS level; I: } n=15, \text { II: } n=29, \text { III: } n=5 \text {, missing } n=5\end{array}$ & $\begin{array}{l}\text { Age } 7, n=14 \\
\text { Age } 8, n=11 \\
\text { Age } 9, n=10 \\
\text { Age } 10, n=8 \\
\text { Age } 11, n=3 \\
\text { Age } 12, n=8\end{array}$ & $\begin{array}{l}8 \hat{\jmath}, 6 q \\
4 \hat{\jmath}, 79 \\
7 \hat{\sigma}, 3 q \\
5 \hat{\jmath}, 39 \\
2 \hat{\jmath}, 19 \\
5 \hat{\jmath}, 3 q\end{array}$ \\
\hline
\end{tabular}

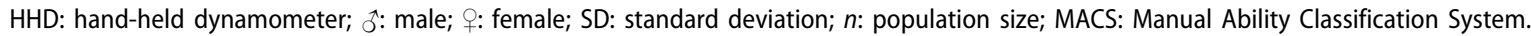




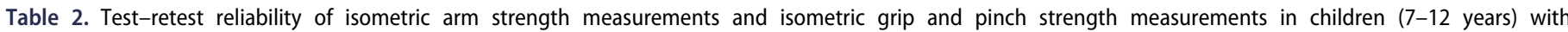
unilateral spastic cerebral palsy.

\begin{tabular}{|c|c|c|c|c|c|c|c|c|c|}
\hline Movement & $n$ & Mean T0 (SD) & Mean T1 (SD) & Diff T0-T1 & ICC & \multicolumn{2}{|c|}{$95 \% \mathrm{Cl}$} & SEM & SDC \\
\hline \multicolumn{10}{|c|}{ Isometric arm strength measurements (HHD) } \\
\hline Wrist-extension $\mathrm{AH}$ & 52 & $28.6 \mathrm{~N}(19.7 \mathrm{~N})$ & $29.7 \mathrm{~N}(18.1 \mathrm{~N})$ & $1.1 \mathrm{~N}$ & 0.964 & 0.938 & 0.979 & $4.97 \mathrm{~N}$ & $13.79 \mathrm{~N}$ \\
\hline Wrist-extension (flexion fingers) $\mathrm{AH}$ & 52 & $32.1 \mathrm{~N}(20.5 \mathrm{~N})$ & $34.0 \mathrm{~N}(19.6 \mathrm{~N})$ & $1.9 \mathrm{~N}$ & 0.948 & 0.909 & 0.970 & $6.32 \mathrm{~N}$ & $17.51 \mathrm{~N}$ \\
\hline Wrist-flexion $\mathrm{AH}$ & 52 & $34.4 \mathrm{~N}(15.2 \mathrm{~N})$ & $36.9 \mathrm{~N}(15.9 \mathrm{~N})$ & $2.5 \mathrm{~N}$ & 0.894 & 0.814 & 0.940 & $6.84 \mathrm{~N}$ & $18.96 \mathrm{~N}$ \\
\hline Elbow-flexion $\mathrm{AH}$ & 52 & $73.3 \mathrm{~N}(30.0 \mathrm{~N})$ & $78.8 \mathrm{~N}(30.2 \mathrm{~N})$ & $5.5 \mathrm{~N}$ & 0.930 & 0.868 & 0.962 & $10.98 \mathrm{~N}$ & $30.45 \mathrm{~N}$ \\
\hline Elbow-extension $\mathrm{AH}$ & 52 & $65.5 \mathrm{~N}(25.8 \mathrm{~N})$ & $70.3 \mathrm{~N}(24.3 \mathrm{~N})$ & $4.8 \mathrm{~N}$ & 0.887 & 0.799 & 0.936 & $11.36 \mathrm{~N}$ & $31.49 \mathrm{~N}$ \\
\hline Wrist-extension NAH & 52 & $57.7 \mathrm{~N}(20.4 \mathrm{~N})$ & $61.2 \mathrm{~N}(19.5 \mathrm{~N})$ & $3.5 \mathrm{~N}$ & 0.905 & 0.830 & 0.946 & $8.38 \mathrm{~N}$ & $23.22 \mathrm{~N}$ \\
\hline Wrist-extension (flexion fingers) $\mathrm{NAH}$ & 52 & $64.0 \mathrm{~N}(26.2 \mathrm{~N})$ & $66.8 \mathrm{~N}(23.3 \mathrm{~N})$ & $2.8 \mathrm{~N}$ & 0.888 & 0.806 & 0.936 & $11.14 \mathrm{~N}$ & $30.89 \mathrm{~N}$ \\
\hline Wrist-flexion NAH & 52 & $68.2 \mathrm{~N}(24.8 \mathrm{~N})$ & $64.5 \mathrm{~N}(24.6 \mathrm{~N})$ & $3.7 \mathrm{~N}$ & 0.932 & 0.878 & 0.962 & $8.85 \mathrm{~N}$ & $24.54 \mathrm{~N}$ \\
\hline Elbow-flexion $\mathrm{NAH}$ & 52 & $104.4 \mathrm{~N}(40.1 \mathrm{~N})$ & $108.2 \mathrm{~N}(38.3 \mathrm{~N})$ & $3.8 \mathrm{~N}$ & 0.958 & 0.927 & 0.976 & $11.12 \mathrm{~N}$ & $30.81 \mathrm{~N}$ \\
\hline Elbow-extension $\mathrm{NAH}$ & 52 & $94.8 \mathrm{~N}(41.1 \mathrm{~N})$ & $97.8 \mathrm{~N}(40.1 \mathrm{~N})$ & $3.0 \mathrm{~N}$ & 0.973 & 0.952 & 0.984 & $9.36 \mathrm{~N}$ & $25.93 \mathrm{~N}$ \\
\hline \multicolumn{10}{|c|}{ Isometric grip and pinch strength (E-link system) } \\
\hline Grip strength $\mathrm{AH}$ & 65 & $5.2 \mathrm{~kg}(4.4 \mathrm{~kg})$ & $4.8 \mathrm{~kg}(3.5 \mathrm{~kg})$ & $0.4 \mathrm{~kg}$ & 0.948 & 0.914 & 0.968 & $1.25 \mathrm{~kg}$ & $3.47 \mathrm{~kg}$ \\
\hline Pinch strength $\mathrm{AH}$ & 65 & $1.7 \mathrm{~kg}(1.2 \mathrm{~kg})$ & $1.9 \mathrm{~kg}(1.1 \mathrm{~kg})$ & $0.2 \mathrm{~kg}$ & 0.940 & 0.896 & 0.965 & $0.37 \mathrm{~kg}$ & $1.03 \mathrm{~kg}$ \\
\hline Grip strength NAH & 65 & $12.6 \mathrm{~kg}(5.6 \mathrm{~kg})$ & $12.2 \mathrm{~kg}(5.3 \mathrm{~kg})$ & $0.4 \mathrm{~kg}$ & 0.942 & 0.904 & 0.964 & $1.81 \mathrm{~kg}$ & $5.02 \mathrm{~kg}$ \\
\hline Pinch strength $\mathrm{NAH}$ & 65 & $3.7 \mathrm{~kg}(1.4 \mathrm{~kg})$ & $3.9 \mathrm{~kg}(1.5 \mathrm{~kg})$ & $0.2 \mathrm{~kg}$ & 0.937 & 0.895 & 0.962 & $0.51 \mathrm{~kg}$ & $1.41 \mathrm{~kg}$ \\
\hline
\end{tabular}

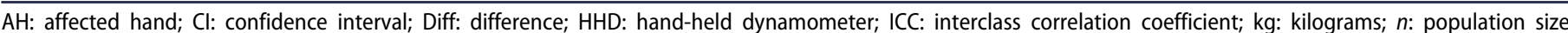
$\mathrm{N}$ : Newton; NAH: non-affected hand; SEM: standard error of the measurement; SD: standard deviation; SDC: smallest detectable change; sig: level of significance.

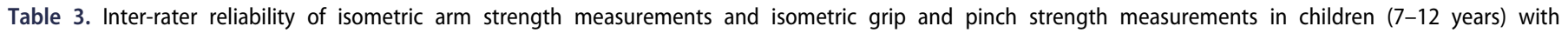
unilateral spastic cerebral palsy.

\begin{tabular}{|c|c|c|c|c|c|c|c|c|c|}
\hline Movement & $n$ & Mean T0 (SD) & Mean T1 (SD) & Diff T0-T1 & ICC & \multicolumn{2}{|c|}{$95 \% \mathrm{Cl}$} & SEM & SDC \\
\hline \multicolumn{10}{|c|}{ Isometric arm strength measurements (HHD) } \\
\hline Wrist-extension $\mathrm{AH}$ & 53 & $25.4 \mathrm{~N}(19.5 \mathrm{~N})$ & $27.9 \mathrm{~N}(19.6 \mathrm{~N})$ & $2.5 \mathrm{~N}$ & 0.963 & 0.932 & 0.980 & $5.26 \mathrm{~N}$ & $14.59 \mathrm{~N}$ \\
\hline Wrist-extension (flexion fingers) $\mathrm{AH}$ & 53 & $28.9 \mathrm{~N}(19.3 \mathrm{~N})$ & $31.0 \mathrm{~N}(18.3 \mathrm{~N})$ & $2.1 \mathrm{~N}$ & 0.919 & 0.860 & 0.953 & $7.31 \mathrm{~N}$ & $20.25 \mathrm{~N}$ \\
\hline Wrist-flexion $\mathrm{AH}$ & 53 & $34.2 \mathrm{~N}(14.5 \mathrm{~N})$ & $35.9 \mathrm{~N}(16.0 \mathrm{~N})$ & $1.7 \mathrm{~N}$ & 0.840 & 0.724 & 0.908 & $8.03 \mathrm{~N}$ & $22.25 \mathrm{~N}$ \\
\hline Elbow-flexion $\mathrm{AH}$ & 53 & $64.1 \mathrm{~N}(24.4 \mathrm{~N})$ & $70.0 \mathrm{~N}(25.5 \mathrm{~N})$ & $5.9 \mathrm{~N}$ & 0.882 & 0.784 & 0.934 & $11.62 \mathrm{~N}$ & $32.21 \mathrm{~N}$ \\
\hline Elbow-extension $\mathrm{AH}$ & 53 & $58.7 \mathrm{~N}(20.4 \mathrm{~N})$ & $60.8 \mathrm{~N}(19.6 \mathrm{~N})$ & $2.1 \mathrm{~N}$ & 0.799 & 0.652 & 0.883 & $11.46 \mathrm{~N}$ & $31.76 \mathrm{~N}$ \\
\hline Wrist-extension NAH & 53 & $50.2 \mathrm{~N}(19.9 \mathrm{~N})$ & $53.3 \mathrm{~N}(20.6 \mathrm{~N})$ & $3.1 \mathrm{~N}$ & 0.878 & 0.789 & 0.930 & $9.02 \mathrm{~N}$ & $25.01 \mathrm{~N}$ \\
\hline Wrist-extension (flexion fingers) $\mathrm{NAH}$ & 53 & $53.3 \mathrm{~N}(24.5 \mathrm{~N})$ & $55.8 \mathrm{~N}(23.1 \mathrm{~N})$ & $2.5 \mathrm{~N}$ & 0.897 & 0.822 & 0.941 & $10.20 \mathrm{~N}$ & $28.26 \mathrm{~N}$ \\
\hline Wrist-flexion NAH & 53 & $56.8 \mathrm{~N}(20.6 \mathrm{~N})$ & $55.3 \mathrm{~N}(18.2 \mathrm{~N})$ & $1.5 \mathrm{~N}$ & 0.886 & 0.803 & 0.934 & $8.59 \mathrm{~N}$ & $23.80 \mathrm{~N}$ \\
\hline Elbow-flexion $\mathrm{NAH}$ & 53 & $90.4 \mathrm{~N}(27.2 \mathrm{~N})$ & $92.8 \mathrm{~N}(30.1 \mathrm{~N})$ & $2.4 \mathrm{~N}$ & 0.913 & 0.850 & 0.950 & $11.59 \mathrm{~N}$ & $32.13 \mathrm{~N}$ \\
\hline $\begin{array}{l}\text { Elbow-extension } \mathrm{NAH} \\
\text { Isometric grip and pinch strength (E-lin }\end{array}$ & 53 & $82.2 \mathrm{~N}(25.8 \mathrm{~N})$ & $82.8 \mathrm{~N}(26.2 \mathrm{~N})$ & $0.6 \mathrm{~N}$ & 0.942 & 0.899 & 0.967 & $8.48 \mathrm{~N}$ & $23.49 \mathrm{~N}$ \\
\hline Grip strength $\mathrm{AH}$ & 54 & $5.9 \mathrm{~kg}(5.3 \mathrm{~kg})$ & $6.1 \mathrm{~kg}(5.1 \mathrm{~kg})$ & $0.2 \mathrm{~kg}$ & 0.976 & 0.959 & 0.986 & $1.32 \mathrm{~kg}$ & $3.65 \mathrm{~kg}$ \\
\hline Pinch strength $\mathrm{AH}$ & 54 & $1.9 \mathrm{~kg}(1.6 \mathrm{~kg})$ & $2.0 \mathrm{~kg}(1.5 \mathrm{~kg})$ & $0.1 \mathrm{~kg}$ & 0.964 & 0.938 & 0.979 & $0.43 \mathrm{~kg}$ & $1.19 \mathrm{~kg}$ \\
\hline Grip strength $\mathrm{NAH}$ & 54 & $13.2 \mathrm{~kg}(7.3 \mathrm{~kg})$ & $13.3 \mathrm{~kg}(7.3 \mathrm{~kg})$ & $0.1 \mathrm{~kg}$ & 0.960 & 0.932 & 0.977 & $1.90 \mathrm{~kg}$ & $5.28 \mathrm{~kg}$ \\
\hline Pinch strength $\mathrm{NAH}$ & 54 & $3.8 \mathrm{~kg}(2.1 \mathrm{~kg})$ & $3.8 \mathrm{~kg}(2.1 \mathrm{~kg})$ & $0 \mathrm{~kg}$ & 0.967 & 0.943 & 0.981 & $0.54 \mathrm{~kg}$ & $1.51 \mathrm{~kg}$ \\
\hline
\end{tabular}

AH: affected hand; Cl: confidence interval; Diff: difference; HHD: hand-held dynamometer; ICC: interclass correlation coefficient; kg: kilograms; $n$ : population size; $\mathrm{N}$ : Newton; NAH: non-affected hand; SEM: standard error of the measurement; SD: standard deviation; SDC: smallest detectable change; sig: level of significance.

\section{Affected hand}

Test-retest ICC values for the IAS measurements varied between $0.887(\mathrm{Cl}$ 0.799-0.936) for the elbow extension and $0.964(\mathrm{Cl}$ 0.938-0.979) for the wrist extension. ICC values for the IGPS measurements were $0.940(\mathrm{Cl} 0.896-0.965)$ for pinch strength and 0.948 (Cl 0.914-0.968) for grip strength. For the IAS, the SDC was $13.79 \mathrm{~N}$ for wrist extension and $31.49 \mathrm{~N}$ for elbow extension. For the IGPS, the SDC was $1.03 \mathrm{~kg}$ for pinch strength and $3.47 \mathrm{~kg}$ for grip strength.

\section{Non-affected hand}

ICC values for the IAS measurements varied between 0.888 (C 0.806-0.936) for wrist extension with flexed fingers and $0.973(\mathrm{Cl}$ 0.952-0.984) for elbow extension. For the IGPS measurements, ICC values were $0.937(\mathrm{Cl}$ 0.895-0.962) for pinch strength and 0.942 (CI 0.904-0.964) for grip strength. The SDC for the IAS was $24.54 \mathrm{~N}$ for wrist extension with stretched fingers and $30.89 \mathrm{~N}$ for wrist flexion. For the IGPS, the SDC was $1.41 \mathrm{~kg}$ for pinch strength and $5.02 \mathrm{~kg}$ for grip strength.

\section{Inter-rater reliability}

For the IAS, 53 children performed all measurements. For the IGPS, the total number of participants was 54 . The inter-rater reliability statistics of the IAS and IGPS are presented in Table 3. There were no missing items.

\section{Affected hand}

Inter-rater ICC values for the IAS measurements varied between $0.799(\mathrm{Cl}$ 0.652-0.883) for elbow extension and $0.963 \quad(\mathrm{Cl}$ 0.932-0.980) for wrist extension. For the IGPS measurements, ICC values were $0.964(\mathrm{Cl} 0.938-0.979)$ for pinch strength and 0.976 (CI 0.959-0.986) for grip strength. The SDC for the IAS was $14.59 \mathrm{~N}$ for wrist extension and $32.21 \mathrm{~N}$ for elbow flexion. The SDC for the IGPS was $1.19 \mathrm{~kg}$ for pinch strength and $3.65 \mathrm{~kg}$ for grip strength.

\section{Non-affected hand}

ICC values for the IAS measurements varied between $0.878(\mathrm{Cl}$ 0.789-0.930) for wrist extension and 0.942 (Cl 0.899-0.967) for elbow extension. ICC values for the IGPS measurements were $0.960(\mathrm{Cl} 0.932-0.977)$ for grip strength and 0.967 (Cl 0.943-0.981) for pinch strength. The SDC for the IAS was $23.80 \mathrm{~N}$ for wrist flexion and $32.13 \mathrm{~N}$ for elbow flexion. For the IGPS, the SDC was $1.51 \mathrm{~kg}$ for pinch strength and $5.28 \mathrm{~kg}$ for grip strength. 


\section{Discussion}

The purpose of this study was to investigate the reliability of maximum isometric UE strength measurements in children aged between 7 and 12 years with USCP using the HHD, and maximum IGPS measurements using the Biometric E-Link Evaluation System, in a high-quality study designed according to the COSMIN criteria [10].

For the IAS measurements in this study, all test-retest reliability ICC values and all inter-rater reliability ICC values, except elbow flexion of the $\mathrm{AH}$, indicated excellent reliability, which is in line with those previously reported by Crowner and Racette [16] and Vaz et al. [4]. However, assessment of the clinometric properties of the HDD was not the main goal of these studies. This could explain their small sample sizes and the limited description of the design of the reliability study. In both studies, information about GMFCS [11] and MACS [12] level was missing. The study of Vaz et al. was performed before the MACS levels were published. In the study of Crowner and Racette [16], only two children were included for the reliability part of the study and in the study of Vaz et al., 11 children. Also, other information about COSMIN design requirements, such as the time interval, was not described. Moreover, for example, in the study of Vaz et al. [4] important information about test conditions and the independence of measurements was not described.

For the IGPS measurements in this study, all test-retest reliability ICC values and all inter-rater reliability ICC values showed excellent reliability. No previous study has reported clinometric properties of the E-link Evaluation system in children with USCP. Nevertheless, the results are in line with those reported in another study involving healthy participants (adults, 18-25 years) [17]. Furthermore, the part of the E-link Evaluation system which was used for determining grip strength shows similarities with the Jamar dynamometer. The reliability of the Jamar dynamometer was reported in the study of Klingels et al., and both test-retest (ICC 0.96) and inter-rater (ICC 0.95) reliability were excellent. This study was rated moderate according to the COSMIN criteria [8]. In terms of appearance, size and function, both instruments are more or less the same. The differences between the Jamar and the E-link are that they have different manufacturers, and the Jamar has incremental steps of $0.45 \mathrm{~kg}(1 \mathrm{lb})$, whereas the E-link Evaluation system has incremental steps of $0.1 \mathrm{~kg}$.

As the present study fulfils the COSMIN criteria for a study with good methodological quality, it can be concluded that almost all arm/hand strength measurements have excellent test-retest reliability and excellent inter-rater reliability in the group of children with USCP, aged 7-12 years. Only the inter-rater reliability of the elbow flexion of the $\mathrm{AH}$ was classified as "good", meaning there was more variability in the performance of this measurement. A possible explanation for this variability in the performance of this measurement could be the higher muscle strength values. With higher muscle strength values, it is more difficult for the therapist to check/control that there is no movement in the joint. Reviewing the above-mentioned results, it can be concluded that both methods can be used reliably for cross-sectional measurements, for example, as a screening instrument or to determine UE strength in children with USCP.

However, besides test-retest reliability and inter-rater reliability, the SEM and SDC-values are important components of reliability [9]. SEM and SDC values for these measurement instruments have not been reported before. With the SEM and SDC values, the usability in patients in clinical practice can be determined, certainly when these instruments are used to determine changes over time in individual patients. In order to correctly interpret changes, for example, after a strength training program, one needs to know how much improvement is necessary to be sure that this improvement is not due to error. So, the change needs at least to be larger than the SDC. Unfortunately, so far, no clear information is available on how much improvement a child with USCP can achieve after a strength-training program. However, in cases where the muscle strength at baseline of a child is already less than the SDC-value, it will be very unlikely that by any intervention one can achieve an improvement (i.e., more than double the strength) above the SDC threshold. So, the utility of both instruments for measuring changes in muscle strength can therefore be a problem in children with USCP with low muscle strength (below the SDC-value). Therefore, currently it is not possible to draw firm conclusions about the usability of both measurement instruments to measure changes over time. Additional research on the effects of strengthening and other interventions of the upper extremities in children with USCP is recommended to draw firm conclusions about the usability of the instruments in clinical practice, especially in children with USCP with low muscle strength.

\section{Limitations}

Age, gender and MACS level were not ideally distributed, and therefore, some of these variables could have influenced the results. As this study population has an age range of 7-12 years, caution is advised when testing children of different age groups. The population size was too small to calculate separate ICC/SEM/ SDC values for each MACS level [12]. Caution is advised when testing children with USCP with MACS-level III, because of the small population of included children. Unfortunately, group size was also too small to determine the specific characteristics of children with a muscle strength below the SDC value. Another limitation of the study could be the high number of measurement therapists, as this could have resulted in higher measurement errors. However, the high number of therapists involved in the measurements resembles clinical practice.

\section{Conclusions}

The HDD and E-link system are usable measurement instruments in cross-sectional measurements of UE muscle strength in children with USCP. It is not clear if both instruments are usable for measuring changes in UE muscle strength within one person, especially if a child with USCP has low muscle strength. Therefore, caution in the interpretation of changes in UE muscle strength is necessary. More research on the effects of strengthening interventions of the upper extremities in children with USCP is recommended. Once the effects of strengthening interventions of the upper extremities in children with USCP have been examined, the usability of all instruments for longitudinal measurements will require reconsideration.

\section{Acknowledgements}

We thank all children and their parents who participated in this study. Also special thanks to the schools and/or rehabilitation centers that participated in this study and to Dr. Caroline Bastiaenen for assistance with the statistics and interpretation of results.

\section{Disclosure statement}

No potential conflict of interest was reported by the authors. 


\section{Funding}

The study was funded by "Stichting Vooruit voor kinderen met een handicap", "Stichting Innovatie Revant" and the "Johanna KinderFonds". The funders had no role in the design, the data collection, analysis, and interpretation; the reporting of this work, or the decision to submit the work for publication.

\section{ORCID}

Koen Dekkers (D) http://orcid.org/0000-0002-3675-5339

\section{References}

[1] Rosenbaum P, Paneth N, Leviton A, et al. A report: the definition and classification of cerebral palsy April 2006. Dev Med Child Neurol Suppl. 2007;49(Suppl. 109):8-14.

[2] Wiley ME, Damiano DL. Lower-extremity strength profiles in spastic cerebral palsy. Dev Med Child Neurol. 1998;40(2): 100-107.

[3] Smits-Engelsman B, Rameckers E, Duysens J. Muscle force generation and force control of finger movements in children with spastic hemiplegia during isometric tasks. Dev Med Child Neurol. 2005;47(5):337-342.

[4] Vaz DV, Cotta M, Fonseca ST, et al. Muscle stiffness and strength and their relation to hand function in children with hemiplegic cerebral palsy. Dev Med Child Neurol. 2006;48(9):728-733.

[5] Braendvik SM, Elvrum AKG, Vereijken B, et al. Relationship between neuromuscular body functions and upper extremity activity in children with cerebral palsy. Dev Med Child Neurol. 2010;52(2):29-34.

[6] Klingels K, Demeyere I, Jaspers E, et al. Upper limb impairments and their impact on activity measures in children with unilateral cerebral palsy. Eur J Paediatr Neurol. 2012; 16(5):475-484.
[7] Faigenbaum AD, Kraemer WJ, Blimkie CJ, et al. Youth resistance training: updated position statement paper from the national strength and conditioning association. J Strength Condition Res. 2009;23(Suppl. 5):60-79.

[8] Dekkers KJ, Rameckers EA, Smeets RJ, et al. Upper extremity strength measurement for children with cerebral palsy: a systematic review of available instruments. Phys Ther. 2014;94(5):609-622.

[9] De Vet HC, Terwee CB, Mokkink LB, et al. Measurement in medicine: a practical guide. Cambridge (UK): Cambridge University Press; 2011.

[10] Terwee CB, Mokkink LB, Knol DL, et al. Rating the methodological quality in systematic reviews of studies on measurement properties: a scoring system for the COSMIN checklist. Qual Life Res. 2011;21(4):651-657.

[11] Palisano R, Rosenbaum P, Walter S, et al. Development and reliability of a system to classify gross motor function in children with cerebral palsy. Dev Med Child Neurol. 1997; 39(4):214-223.

[12] Eliasson AC, Krumlinde-Sundholm L, Rösblad B, et al. The Manual Ability Classification System (MACS) for children with cerebral palsy: scale development and evidence of validity and reliability. Dev Med Child Neurol. 2006;48(7): 549-554.

[13] Haahr M, Haahr S. RANDOM.ORG [APP]. 2.3. Ireland: Randomness and Integrity Services Ltd; 2018.

[14] Mayhew T, Rothstein J. Measurement of muscle performance with instruments. Measurement in physical therapy. New York: Churchill Livingstone Inc.; 1985. p. 57-102.

[15] Portney LG, Watkins MP. Foundations of clinical research: applications to practice. Upper Saddle River (NJ): Prentice Hall Health; 2000.

[16] Crowner BE, Racette BA. Prospective study examining remote effects of Botulinum toxin a in children with cerebral palsy. Pediatr Neurol. 2008;39(4):253-258.

[17] Allen D, Barnett F. Reliability and validity of an electronic dynamometer for measuring grip strength. Int J Ther Rehabil. 2011;18(5):258. 